\title{
UTILIZING VIRTUAL REALITY TECHNOLOGY IN THE PRESERVATION OF ARCHITECTURAL HERITAGE: AN EMPIRICAL STUDY OF THE LOCAL ARCHITECTURE OF HIJAZI IDENTITY IN THE MECCA REGION OF SAUDI ARABIA
}

\author{
REEM F. ALSABBAN \\ University of Jeddah, Saudi Arabia
}

\begin{abstract}
Architectural documentation is considered one of the first processes that take place in the preservation of historic and archaeological buildings. The emergence of the digital revolution and what it brings from modern technologies provide a new way to document and archive these historic locations. Due to the historical value of these buildings and their status in local heritage, it was deemed important for these locations to be archived in a way that helps in availability and ease of access for scholars and researchers. This paper outlines some methods that reach this goal, alongside an applied example of a historical building (a Hijazi palace in the Mecca Region) modeled in virtual reality. This paper is divided into two sections. The first section focuses on methods of archiving historical locations, while the second focuses on the applied example of the use of VR in archiving. It concentrates on the details of interior architecture to help researchers of interior design. These details have not previously been given attention due to the difficulty of reconstructing life in the time period, and the scarcity of reliable sources on the subject. However, utilizing photographic evidence, some historic illustrations, field visits of other historic buildings of the period, and visits to houses containing personal possessions of people who have lived in these buildings, it is possible to reconstruct spaces from the period in a way that depicts the fine details that represent the lives of the inhabitants of these historic buildings.
\end{abstract}

Keywords: architectural heritage, virtual reality, local architecture, Hijazi identity, Mecca region.

\section{INTRODUCTION}

Arab countries have received a tremendous inheritance in the form of urban heritage. Generations toiled to create buildings shaped by customs, traditions, necessity, and environmental conditions. The care for these monuments is a field that brings the legacy of the past together with the technology of modern times. Cohesion between the historic and the contemporary is necessary to not deviate from investing in our rich heritage because of modern developments, and to utilize it in our modern age without it becoming a liability on development [1]. Conservation of urban heritage and historical locations in Muslim countries is facing threats. Preserving the heritage of previous civilizations is important as it has impact on the identity of the people. Urban heritage tells the tale of people through the ages and the evolution in the way the environment could be harnessed. From predecessor to successor, legacy is passed through the ages. This is not exclusive to language, thought, and literature - but is inclusive of all material and sentimental elements of the society. Thought, philosophy, religion, science, art and architecture to name a few.

In the past century, humanity has seen the fragility of urban and human heritage against the destruction of war and modern weaponry. With the disappearance of numerous historical buildings in WWII, awareness of the importance of preserving urban heritage from demolition became clear. Despite time taking its toll on these buildings with decay and catastrophic floods and earthquakes, the natural destruction of these locations does not come close or that of humans. Our modern technology has accelerated urban development, causing 
the swift disappearance of buildings that would be of historical value in favor of roadways and large public and industrial urban projects. This surge in urban development has also caused the increase of pollutants in the air, from vehicle exhaust and factory emissions. Which lead to the acceleration in decay of buildings of historical significance [2].

Considering the difficulty of obtaining historic and scientific sources and information on urban heritage, this paper showcases useful sources and methods that can be used and relied upon when archiving urban heritage. Comparisons between archiving methods will also be provided, making them more accessible and to help researchers looking to utilize these methods in future projects. The Mecca region has been chosen as a sample location for the paper due to recent developments in the city accompanying the expansion in the holy mosque that required the destruction of several historical buildings inside the construction area. This development demanded a modern solution for archiving that emulate reality, like VR technology, which allows a viewer to inspect sites of urban heritage by entering a virtual world portraying life in past periods with all its intricate architectural detail.

\section{LITERATURE REVIEW}

The paper by Shawkat [3] studied the process of architectural archival of historical location using digital means, and the impact of communication technology on the process of exchanging experiences between entities interested in the preservation of urban heritage to enable researchers and policymakers reach decisions that are constructive for the field. A paper by Rashed [2] reviewed an example of the employment of modern technology in the registrations and documentation of urban heritage sites. Displaying the archive for scholars and the public on the internet with their choice of language, reason for visit, and the information that they would want to learn while still preserving the intellectual property of the designer of the site. In some of these projects, it is possible to include an audible and visual program for the site to enjoy the organic aspects of the heritage site, and 3D models of specific aspects of the design, which allows for the addition of details and aspects that were lost. To ensure the success of the work, it is necessary to collaborate with specialized bodies and form a plan to manage and employ data. Lastly, the documentation of heritage allows for the exchange of information and provides an opportunity for distance education, as well as making the information available for further analysis and discussion. The project by Koehl et al. [4] aims to create a virtual visit to a historical building, where it is possible to make a visit while being far away while enriching the experience by the inclusion of information on the architecture and decoration used at the time. Panoramic photography technology was used and tested in natural and artificial light, and the results of the project were reviewed using modern technologies including virtual reality.

In many past papers in the field of urban documentation, the technologies used were limited and relied on some methods without others. Which necessitated outlining crucial sources and methods in a paper, with comparison between said methods, for researches to be able to compare and choose between them. This was one in the first section of this paper.

\section{ARCHIVAL OF ARCHAELOGICAL BUILDINGS}

The term "archaeological site" can be used to refer to any site that has lived for 100 years or longer, if it is of historical value. It can also be defined as a place that instills a sense of awe, and the desire to learn more of the culture that has shaped its creation, for what it displays of aesthetic, historical, political, and symbolic value.

The process of documentation is considered one of the earliest fields of scientific research. It is a scientific look on events of the past, providing precise facts to develop insight on the present through history. 
Article 5 in the National Architectural Heritage Record states that each of the participating countries are to create a record for its urban heritage. Pinpointing buildings, sites, and areas of urban heritage that should be protected, and preserving, documenting, and studying them, while taking the necessary measures to provide quick documentation if the circumstances require it in an emergency.

Methods of urban documentation of archaeological sites vary and evolve through the ages with different techniques and depend on the nature of the site and its historical significance. These methods rely mainly on registration and classification, photographic documentation, and engineering surveillance. Methods of architectural documentation can be divided into two sections.

First section: Traditional methods that rely on manual labor, and individual talent. Carried through traditional tools and manual methods. Traditional methods of building documentations, be it urban or architectural, have displayed accuracy and flexibility as a method of information documentation. This method is characterized by its availability, simplicity, and relative low cost compared to modern high-sensitivity archiving devices.

Second section: Modern methods, also referred to as electronic documentation, use modern technology to archive and collect data. And to pave the way for scholars and researchers interested in archaeological buildings and their documentation, a table has been created that lists the most commonly used methods used in the process of collecting data and documenting them and compares the methods in the parameters of: ease of finding information, availability, clarity, cost, ease of documentation, authenticity, and accessibility. This allows scholars and researchers to focus on their projects by saving time spent researching and studying the various methods of documentation, and in the process helps in the advancement of science. Table 1 showcases the comparisons.

\subsection{Traditional methods of documenting and recording historical data}

Traditional methods are considered one of the most important methods of collecting unique information. They rely on research, investigation, exploration and interpretation. The most important traditional methods are as follows.

\subsubsection{Storytellers}

Individuals that are invested in transferring historical news and incidents and are renowned for that. They hold unique information and memories that some of them have witnessed and lived through, and they add an emotional aspect to the information that researchers can benefit from.

\subsubsection{Stories and novels}

Historical stories and novels illustrate events and describe scenes in a creative way. This can be used to visualize buildings and spaces with increased privacy such as everyday spaces and ladies' wings.

\subsubsection{Poetry}

Some poems describe places and sites, and they are often used to identify a specific historical era or describe a building or a monument.

\subsubsection{Paintings}

Paintings showcase daily life and revive it. They are considered as a vital source for designers, especially those interested in the details of architectural interiors and motifs and contents of interior spaces. 


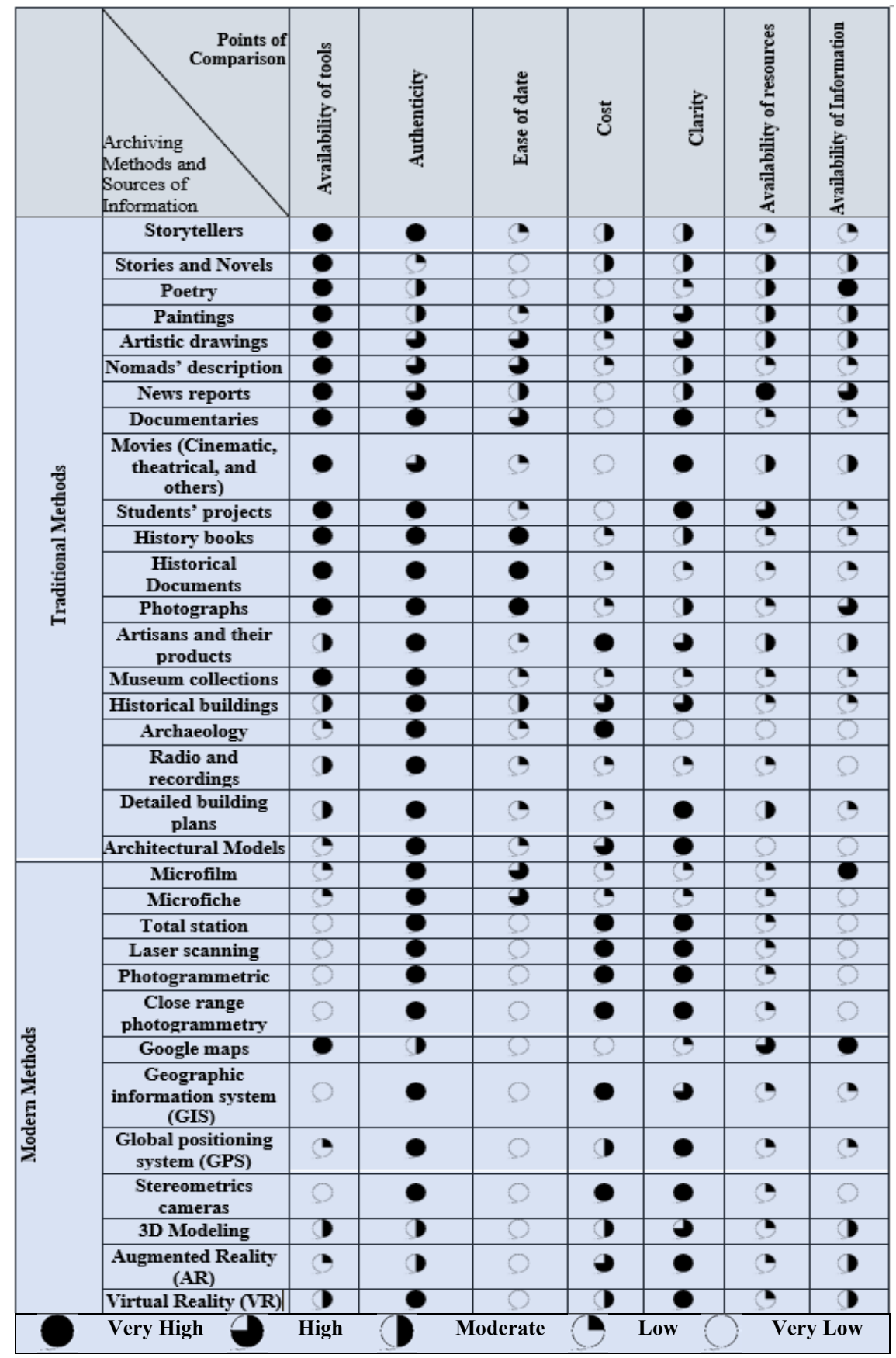

Table 1: Comparison between methods of archiving.

\subsubsection{Artistic drawings}

Drawings include fine details that have been used as sources throughout history; they can also be used to collect some information through reading and analyzing motifs and buildings. 


\subsubsection{Nomads' description}

Nomads' books describe the places they have been to, how they were fascinated by some of them, and describe their feelings towards some others, which allows to collect unique information through that description.

\subsubsection{News reports}

News reports are often filled with unique information that guides researchers, and they can open many doors for research, investigation, and extracting facts.

\subsubsection{Documentaries}

Some documentaries are a real treasure as they present facts and conduct real-life interviews and visits that greatly assist researchers.

\subsubsection{Movies (cinematic, theatrical, and others)}

Some movies and plays illustrate scenes in a way that mimics reality and allows the audience to live the event, highlighting some details of the site.

\subsubsection{Students' projects}

Students' projects depend on field visits and survey of the site, and they are considered a rich source of information.

\subsubsection{History books}

History books are rich with unique and thorough information, often detailing some events and dating them accurately.

\subsubsection{Historical documents}

Historical documents document the history of a building, and often contain historical names of individuals that had a role in constructing a certain building.

\subsubsection{Photographs}

After the invention of the camera, photographers emerged and then travelled the world taking photographs.

They documented their independent journeys and those taken accompanying officials and significant figures, taking photographs of historical sites and buildings on their way which currently present a vital source of information.

\subsubsection{Artisans and their products}

Local artisans played a big role in transferring the heritage of a place to generations and preserving it, and for that, their products can assist research greatly.

\subsubsection{Museum collections}

With nations' efforts in preserving heritage and building historical museums and their attention to showcase historical monuments and artifacts, it became easier for researchers to get their hands-on collectibles and valuable items and use them in their research.

\subsubsection{Historical buildings}

Some historical buildings still stand to this day as monuments of the past. They are considered national treasures that all countries should preserve. They are also a rich source of information for researchers that no other can match. 


\subsubsection{Archaeology}

Historical sites and artifacts contribute greatly to reading the past and recalling it. They assist researchers in their research and projects, but they may require relatively expensive technologies and equipment to visualize their original look in some instances.

\subsubsection{Radio and recordings}

Audio libraries are a rich source for dating, documenting and describing some events.

\subsubsection{Detailed building plans}

Detailed plans of some historical sites and buildings are a vital source of information as they include original measurements and dimensions such as length, width and height. Their details support engineering and design researches.

\subsubsection{Architectural models}

Engineering models made of gold, silver, wood, and other sustainable materials enable the visualization of buildings in their original conditions.

\subsection{Modern methods of documenting and recording historical data}

\subsubsection{Microfilm}

It is the sensitive film that is considered a miniature photographic recording of a written or printed text. This film can be presented on a bigger screen to enlarge the text and simplify reading it, and it requires specialized equipment often available at public libraries.

\subsubsection{Microfiche}

It consists of a flat film card that shows frames organized vertically or horizontally, and is usually the size of a typical card, that is $148 \mathrm{~mm}$ height and $105 \mathrm{~mm}$ width, each card having 60 frames in general.

The number of frames per card can be increased if the minimization ratio is increased, which depends on the quality of paper originals, the minimization ratio used, and the specifications of the equipment used, as each card can hold up to 3000 frames, also known as Ultrafiche.

\subsubsection{Total station}

Total station is used to find the plan and elevation projections of the building. It does that by using machines that calculate the coordinates after collecting them from several points inside and outside the building.

After that, it connects them to a computer device that uses a software package to connect these points.

\subsubsection{Laser scanning}

It is a modern method that uses laser beams to directly scan a body without a physical touch. This produces a three-dimensional point cloud of the scanned body that is then processed to produce a $3 \mathrm{D}$ model of the body.

\subsubsection{Photogrammetric}

Photogrammetry is known as the field of measuring or dimensioning using photos. It initially started as a method to add the third dimension to aerial photography maps, after that, it has been used in many other fields far from typographic maps. Single or double metric cameras can both be used in this method. 


\subsubsection{Close range photogrammetry}

A technology that is based on taking several shots of buildings' facades using cameras and processing these shots using certain software packages.

\subsubsection{Google Earth \& Map}

Historical maps can be obtained using Google maps, which has a feature that allows the user to go back in time and see what the maps looked like several years in the past. It also has a feature that allows browsing some sites and buildings, seeing inside some of them, and producing $3 \mathrm{D}$ models of some others.

\subsubsection{Global positioning system (GPS)}

A method of capturing spatial information of the Earth's surface using satellite images, which has a distance that is further away from aerial photography. Yet, aerial photography differs in that it allows to produce a $3 \mathrm{D}$ model view.

\subsubsection{Geographic information system (GIS)}

It relies fundamentally on computer software packages that can combine information from different sources, producing to the user information that is broader and more accurate than those produced individually from the different sources. For example, these programs can combine ground information collected from Total Station with GPS information, and information from aerial and satellite images to enrich the knowledge of users and assist them - after processing those information - in gaining deep understanding of the studied phenomena and reaching an appropriate decision [8].

\subsubsection{Stereometrics cameras}

A method of taking photographs of $3 \mathrm{D}$ objects in order to measure them using pictures.

\subsubsection{Photometric camera}

This machine combines both photographic and metric documentation. It can be used to record information or send it directly to any place in the world, and it is used to define historical sites, process them, or archive their data.

\subsubsection{D modeling}

Models that mimic reality can be designed using various software packages and electronic devices specialized in demonstrating 3D buildings, and such including architectural details and modeling it to reflect reality.

\subsubsection{Augmented Reality (AR)}

A technology that allows the transformation of $2 \mathrm{D}$ pictures into interactive $3 \mathrm{D}$ ones. It has also been defined by Yuen et al. [5] as a technology method that enhances real world through the content produced by computers. It allows seamless addition of digital content to realize the user's perception of reality as 2D and 3D objects can be added, as well as video, audio, and text files. These tools can also work on enhancing an individual's knowledge spectrums and their understanding of their surroundings.

\subsubsection{Virtual Reality (VR)}

$\mathrm{VR}$ is defined as an interactive 3D environment designed using computer programs. VR surrounds users and transfers them to an imaginary world that seems realistic (VR can be either imaginary or mimicking reality), and this reality can be interacted with through interactions between the virtual environment and the users' senses and actions. 


\section{USE OF VIRTUAL REALITY (VR)}

Virtual architecture enables the individual to participate in designing the building by seeing it in the virtual reality environment, which fulfils one of the social needs, in addition to predicting the outcome of the final build, and the ability to move inside its voids and spaces in order to validate the building's ability to fulfil its desired function. Digital void is part of the imaginative reality, as it creates different three-dimensional versions based on time and movement factors, and it constitutes one of the applied tools of virtual reality. The VR experience aims to enable the user to experience life inside the building, such that the user can walk inside the void designed by a computer and imagine its existence in the current void and interact with it. These applications fall under the realm of demonstrating architectural works and visualizing them in a way that benefits students and researchers.

\subsection{VR potential}

VR has entered many fields, some scientific and technological, such as engineering, medicine, design and arts. VR is considered one of the best tools that demonstrate ideas as it tests different environments in various locations and settings. In addition to using advanced technology with the aid of modern computer programs and software packages that test users and make them feel satisfied. AR and VR technologies are used in flight simulation for example, education and entertainment, and the medical, architectural and design sectors.

Gartner [6], the renowned global research and advisory company, has published its 2018 annual report that details the expected "Hype Cycle" of modern technologies and applications. It predicts that AR and VR technologies will remain growing steadily despite challenges, and their sector will witness growth in various fields as shown in Fig. 1.

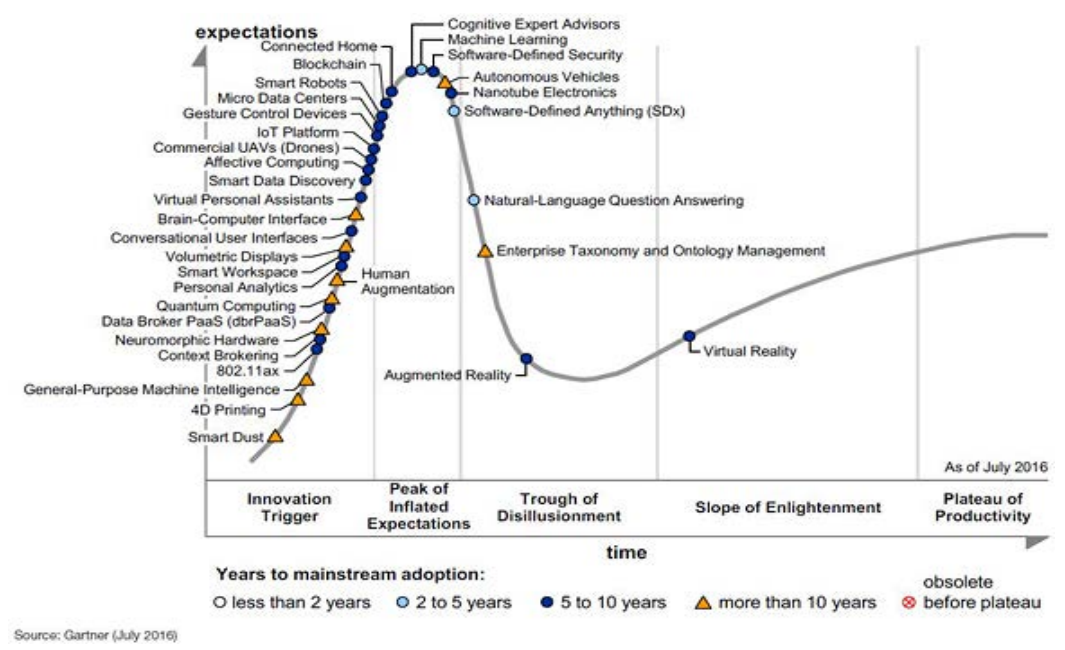

Figure 1: A graph illustrating Gartner's curve of modern applications adoption cycle.

\subsection{The applied project}

After demonstrating the available archiving tools and information sources that assist in electronically archiving historical building in Makkah region, a historical palace was chosen as a model for historical buildings in Makkah, and it is one of the residential palaces that still 
stand to this day (Bin Sulaiman Palace). This palace was built in $1935 \mathrm{AH}$, and it was owned by his highness Shaikh Hamad Al Sulaiman, the minister of state in the early days of Saudi Arabia. The palaces' buildings were designed to fulfil the needs of such role, as there are residential buildings for the Shaikh's family in the north wing, while the central buildings are devoted to hosting parties and ceremonies, hosting dinners, and for important guests to reside in. As for the building in the south side, its front section has been designated to official receptions and meeting visitors, while the guards and servants' residences are in the back section. The annex seems to have been used for general services, as one can notice a space were the pumps room could be in the south-western section of the annex, and an "Iwan" (vaulted space) open to the annex's own courtyard in the middle section.

The palace consists of three main building: northern, central, and southern, in addition to an annex attached to the southern side of the building. The building is surrounded by several outer yards and patios with doors opening to the buildings' courtyards in the front section (west) and back section (east).

One can notice that the designer has taken the building site's topographical nature into account and utilized it to the building's advantage by benefitting from the natural ground incline. This contributed to the gradual distribution of voids and spaces in the buildings' different floors, in addition to its reflection on the external building block.

\subsubsection{The palace's architectural character}

The use of the traditional Hijazi architectural character, especially the Makkah character, is evident in the building (see Fig. 2). Particularly, it can be seen in the use of the "Roshan" and wooden windows finished with circular or straight ends, considering their different dimensions, sizes, and types based on the functions they serve.

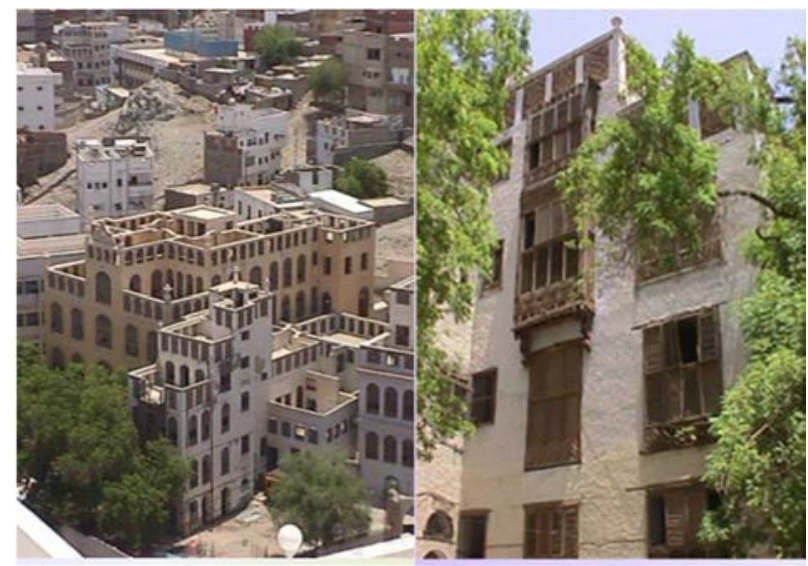

Figure 2: Pictures of Bin Suleiman's palace buildings from the outside.

The rise of the part that forms the ceiling is noticeable in the facades of the southern building, alongside the use of decorations and motifs in the northern one. One can also notice the use of colored brick in slabs and surfaces, as well as the chimney configuration and cylindrical ventilations for bathrooms and kitchens from the upper surfaces. Wrought iron was also used in the lower floors and open parts of the Roshan and windows for security. 
The building is rich with motifs and gypsum designs that came to existence through decoration works on ceiling screens, door and window frames, and interior ceilings. In addition to coloring and dying works and drawing on reception room and bedroom walls and bathroom domes. The building is a true architectural masterpiece reflecting a side of Makkah's urban heritage in the middle of the 14th century AH [7].

\subsubsection{Project stages}

In this project, various methods and tools were used to archive the building using modern technologies, and to enable visiting it in the virtual world. The project started by using newspapers article, followed by a field visit to the palace, taking photograph of its interiors using a camera. After that, several storytellers were contacted to hear their description of the buildings and voids in that Era, then, academic researches and projects were used to collect engineering drawings and plans of the buildings as well as some vital information. Painting that visualize the building's internal voids and the historical daily living were also used, in addition to visiting a personal museum to study historical artifacts. That information was collected in order to fully visualize the space in preparation to upload data to modern software packages and import them to virtual reality programs to produce a result, with the addition of icons that show some information about the pieces used inside the space. Fig. 3 shows those different stages.

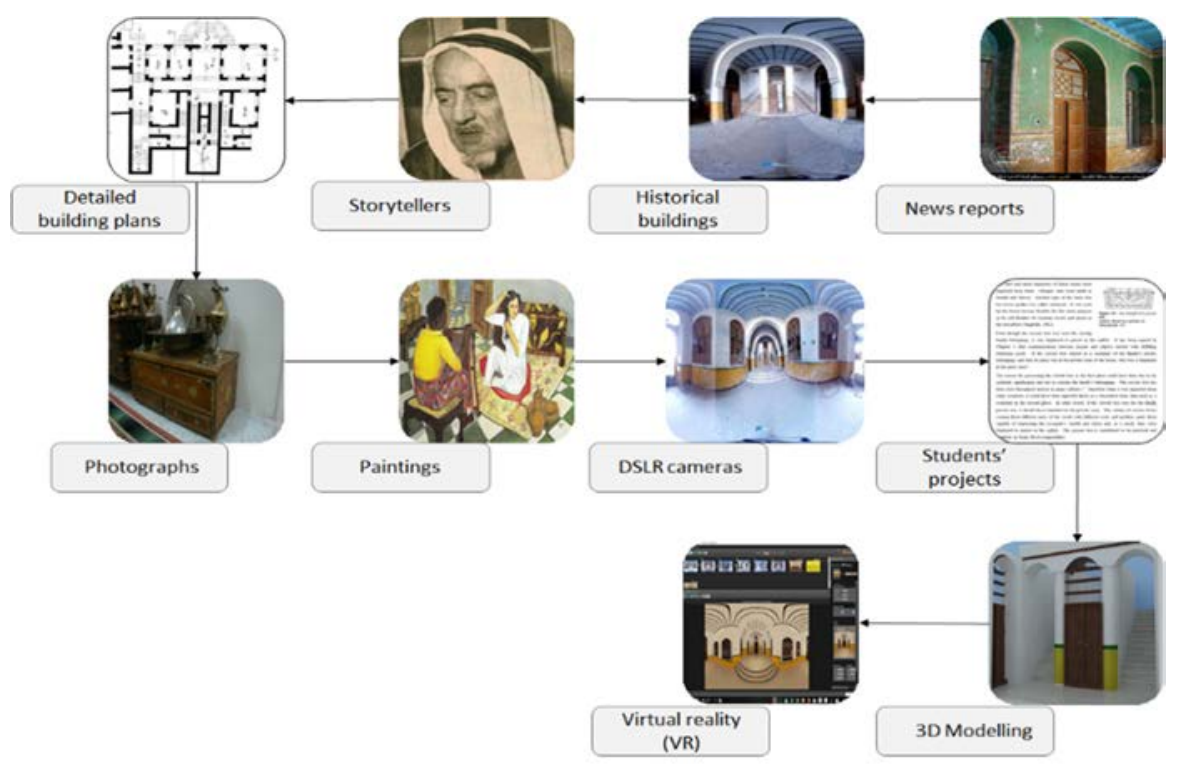

Figure 3: The stages of the applied project and the courses of information used to achieve the final result.

\subsubsection{Discussion of results}

3D models of the palace were developing using the software: 3D Max 2018. Additionally, panoramic shots of the palace's voids were taken and uploaded to Pantour Pro 2.5 KOLOR, a software that converts 360-degree pictures into a virtual environment that that can be explored through hotspots icons. When clicked on, a window appears displaying information about the piece or element inside the void from certified sources, or a link showing a painting 
that contains the same element. This window can also be linked to other website in the web, making it easier for the learner to reach information and utilize them. Fig. 4 shows examples of those results.
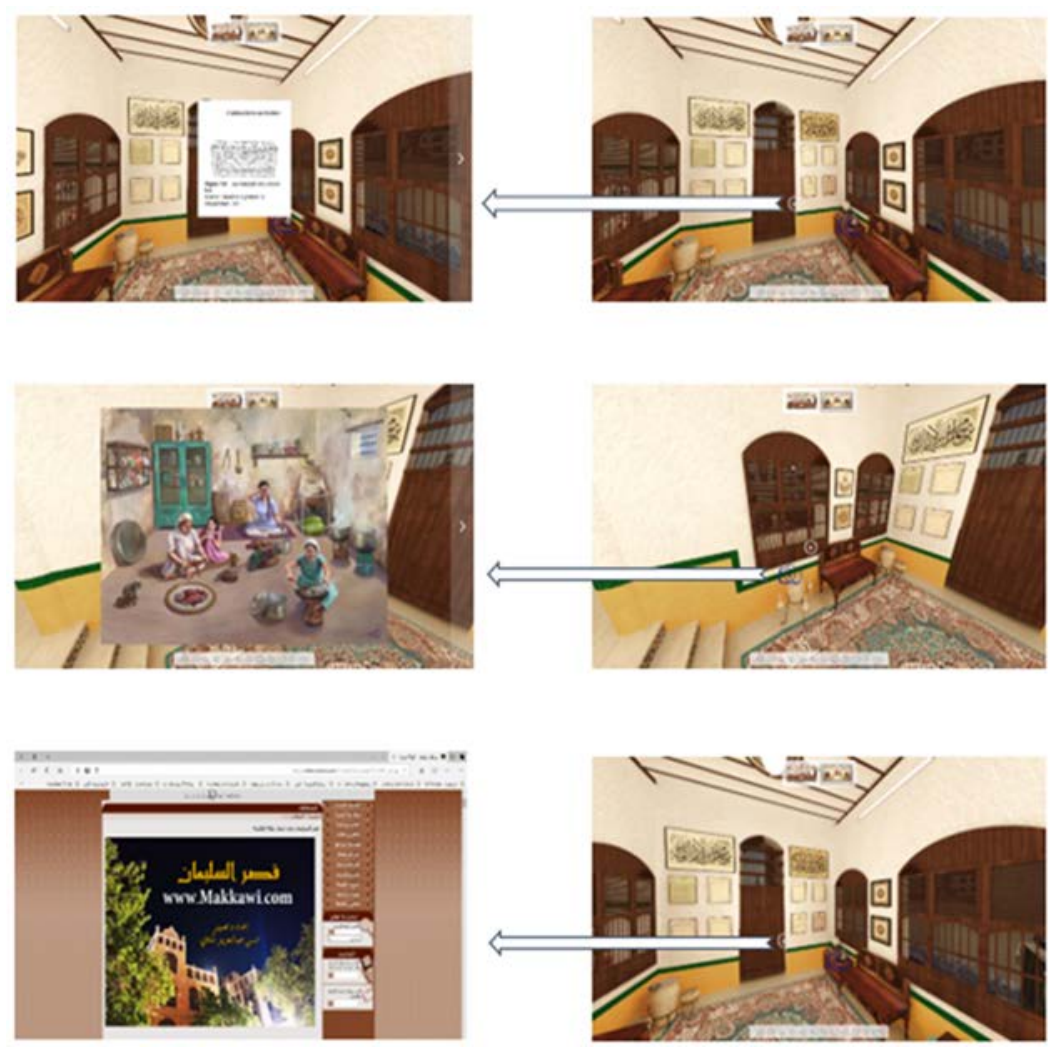

Figure 4: A photo illustrating the use of virtual tour technology in Bin Suleiman Palace utilizing the function of extracting important information of the void by clicking on different icons.

\section{CONCLUSION}

Preserving the urban heritage became a historical human responsibility, in order to contribute to preserving the landmarks of the past for the future generations to see. Ever since humans became aware of the historical inevitability of the past, present and future they tried to try to register the present and preserve the past. As the cultural flow of global civilizations continues, the preservation of cultural identity has become a fundamental objective, which happens through the preservation of urban heritage.

This paper discusses traditional and modern ways and means of archiving historic buildings; to facilitate researchers and designers the access to the best way and method to study the urban heritage. Furthermore, this paper includes an applied part were several methods has been utilized to employ modern technology in the design of a historical building with a Hijazi identity, allowing to tour around the building and learn about its architectural elements using virtual reality technology. 


\section{RECOMMENDATIONS}

Emphasizing employing modern technology in the public education curriculum that are concerned with the transfer of heritage and identity. Utilizing modern technology in guiding future generations towards strengthening their national identity. The necessity of electronic archiving of urban heritage to include audio, visual, written and verbal aspects.

\section{REFERENCES}

[1] ALECSO, Architectural heritage conservation charter in Arab countries, 2016.

[2] Rashed, A., Sustaining Architectural Environments: Documentation as Preservation of Urban Architecture: Case Study of Rumailah Castle in AlEin, United Arab Emirates, 2002.

[3] Shawkat, et al., Architectural documentation of historical buildings in the digital revolution. Presented at Sixth International Architectural Conference "The Digital Revolution and its Effects on Architecture”, Assiut University, Assiut, 2005.

[4] Koehl, M. et al., Documentation of historical building via virtual tour: The complex building of baths in Strasbourg. Presented at International Archives of the Photogrammetry, Remote Sensing and Spatial Information Sciences, Volume XL-5/W2, 2013 XXIV International CIPA Symposium, Strasbourg, France, 2013.

[5] Yuen, S. et al., Augmented reality: An overview and five directions for AR in education. Journal of Educational Technology Development and Exchange, 4(1), 2011.

[6] Gartner, 5 trends emerge in the Gartner Hype Cycle for emerging technologies 2018. www.gartner.com/smarterwithgartner/5-trends-emerge-in-gartner-hype-cycle-foremerging-technologies-2018/.

[7] Ibn Sulaiman Bajrool Palace's documentation team from the College of Engineering and Islamic Architecture in Umm Al Qura University-Mecca, 2012. 